\title{
Research and Design of Rectangular Slot Microstrip Patch Antenna with Stripline Feeding
}

\author{
Prasad Janga
}

\begin{abstract}
As of late the improvement in correspondence framework requires the advancement of ease, negligible weight, low profile radio wires that are equipped for keeping up elite over a wide range of recurrence that is the reason mechanical pattern has concentrated on structure of microstrip fix receiving wire .The point of this paper is to plan a rectangular microstrip fix reception apparatus for remote applications and concentrate the impact of different reception apparatus parameters, for example, execution of radio wire as far as increase, radiation design, return misfortune and VSWR and so on. The proposed antenna operates at $2.6734 \mathrm{GHz}, 1.1809 \mathrm{GHz}, 2.9899 \mathrm{GHz}$ and $5.8392 \mathrm{GHz}$ suitable for radio, GSM, Auto-toll roads and container tracking. The radiation pattern obtained is omnidirectional that is it will radiate and receive energy equally well in all directions. Return loss is less at that point - 10dB which means in any event $90 \%$ info power is conveyed to gadget and reflected power is under $10 \%$..
\end{abstract}

\section{INTRODUCTION}

These days, remote correspondence frameworks are winding up progressively popular [1].The field of remote interchanges has been developing since the creation of convenient cell phones a few decades back. Some remote gadgets are required to help different remote administrations and high information rate [2]. Wireless correspondence includes the transmission of data over a separation without the assistance of wires and links or some other type of electrical conduits. It has carried much progression with its viable highlights. Remote gadgets can be utilized for cell communication, remote access to web, GPS units, remote PC, satellite TV and cordless telephone. [3] Wireless activities grant administrations, for example, long-run correspondences, that are inconceivable or unfeasible to execute with the utilization of wires. The term is generally utilized in the media communications industry to allude to broadcast communications frameworks (for example radio transmitters and collectors, remote controls, and so forth.) which utilize some type of vitality (for example radio waves, acoustic vitality,) to move data without the utilization of wires. Data is moved thusly over both short and long distances. [4]

Microstrip fix receiving wire are the most one utilized for remote correspondence [5]. Radio wire is one of the essential structure squares of remote applications. Reception apparatus assumes a significant job in media transmission industry and is utilized to transmit and gather electromagnetic (EM) waves. [6] The improvement of exceptionally effective, low-profile, little size, multi-band and wide band receiving wires that can be made inserted

Revised Manuscript Received on September 10, 2019.

Dr. Prasad Janga, Professor, Department of ECE, CMR Institute of Technology, Hyderabad, Telangana, India

(Email: prasadjanga85@gmail.com). into remote items are especially requested. As of late microstrip receiving wire have been one of the most researchable and creative thought in reception apparatus hypothesis. The microstrip receiving wires have various helpful highlights, for example, low profile, light weight, conformal molding, minimal effort, and straightforwardness of assembling and simple reconciliation to microwave circuit board.[7] Beside the points of interest, it has a few weaknesses and one of the real drawbacks is restricted data transmission and the specialist are attempt to build transfer speed. The emanating patch might be square, rectangular, roundabout, and triangular. Out of these the rectangular fix is by a long shot most generally utilized design [8]. It is anything but difficult to analyze by transmission line model. Single band fix receiving wire can be adjusted into a double band, triple band or multiband reception apparatus by presenting openings in the fix at suitable position. A microstrip space radio wire is a sort of the reception apparatus, having openings on the geometry plane of microstrip fix. The shape and position of the openings assume a significant job in deciding the reverberation frequency[9]. At the point when the space is cut either quarter wave long or half wave long at a suitable position inside the fix, it energize the another mode close to the principal method of the fix and that gives us double or multi recurrence response.[10] It can be utilized in an expansive scope of frequencies generally from $1 \mathrm{GHz}$ to $100 \mathrm{GHz}$.

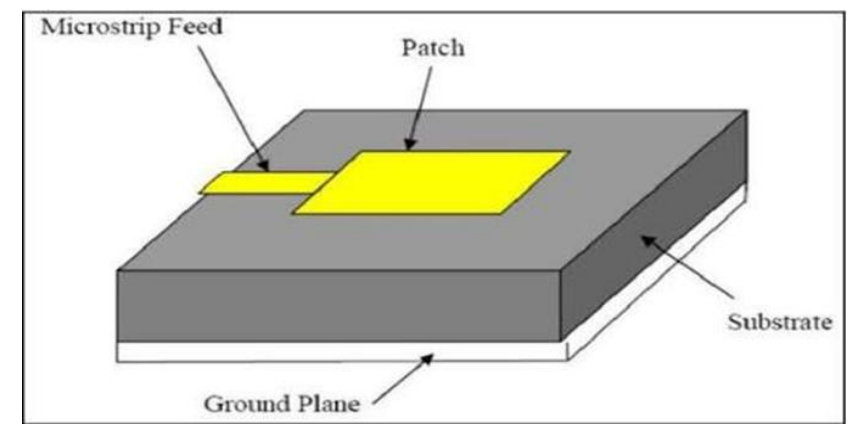

Figure 1: Rectangular Microstrip Patch Antenna

The straightforward Microstrip fix receiving wire comprise of a dielectric substrate having fixed dielectric consistent. Emanating patch is available on one side of a dielectric substrate and a ground plane is available on opposite side of substrate. The metallic fix may take any geometrical shapes like rectangular, roundabout or triangular, helical, ring, circular and so on. Round fix reception apparatus offers about $8 \%$ higher data transfer

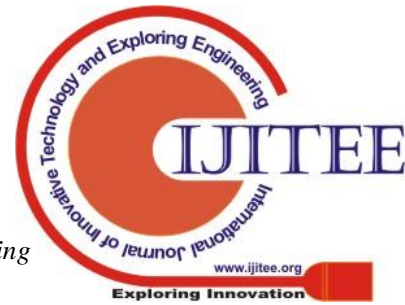


capacity and almost $2.0 \mathrm{~dB}$ less side projection control than that of rectangular fix antenna. [11] Circular\& elliptical shapes are somewhat littler than rectangular patches, so they will have littler bandwidth \& gain. [12] Radiation Pattern alludes to the directional reliance of the quality of the radio waves from reception apparatus or to the source. [13] The radiation example of a radio wire is a graph of field quality or all the more regularly the power force. All the receiving wire configuration ought to accomplish great radiation proficiency there is a need of detachment between framework ground plane and the antenna.[14] To improve gains, Phased Array Antenna(PAA) is a different radio wire framework wherein radiation example can be fortified specifically direction \& suppressed in undesired ways. [15] To emanate receiving wire a feed is utilized to energize by immediate or backhanded contact and feed can have numerous designs like microstrip line, coaxial, gap coupling and nearness coupling.[16]

\section{GEOMETRICAL VIEW OF PROPOSED ANTENNA:}

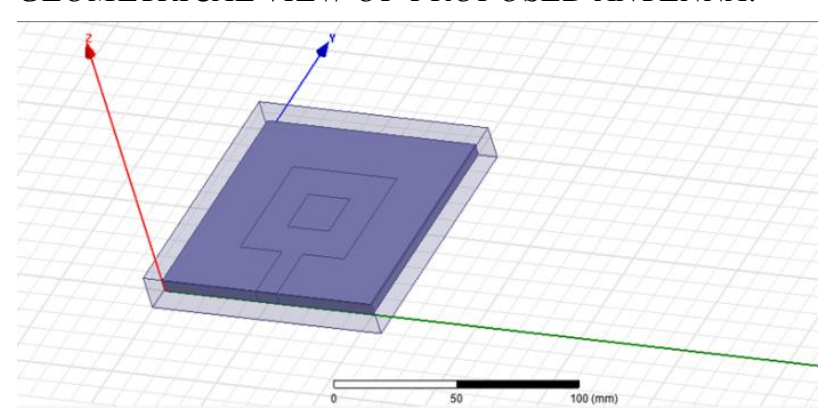

Figure 2: Geometrical Design View

Figure 2 shows geometrical design view of proposed antenna. Here material used in the substrate is "FR4_epoxy" which has permittivity $\mathrm{Er}=4.4$. [17] The position of the substrate is $(0,0,0)$. The length, breadth and height is $100 \mathrm{~mm}, 100 \mathrm{~mm}$ and $5 \mathrm{~mm}$ respectively. The position of ground is $(0,0,0)$. The length and widthis $100 \mathrm{~mm}, 100 \mathrm{~mm}$ respectively. It has been assigned a boundary of Perfect $\mathrm{E}$ as it models a perfectly conducting surface which forces electric field to be normal to the surface. The position of rectangular patch is $(25,25,5)$ and has length and width $50 \mathrm{~mm}, 50 \mathrm{~mm}$ respectively. The position of port is $(45,0,0)$. The length \&height of port is taken as $10 \mathrm{~mm}$ and $5 \mathrm{~mm}$. The position of feed line is same as that of port. The length of feed line is $10 \mathrm{~mm}$ and width is $25 \mathrm{~mm}$. The antenna is covered in a radiation box having the position $(-5,-5,-5)$ and have length, width, height as $110 \mathrm{~mm}, 110 \mathrm{~mm}, 15 \mathrm{~mm}$ respectively. It is done as such as to show free space radiation and radiation limit is utilized to imitate free space by truncating unending free space to limited figuring domain.[18]

\section{DESIGN PARAMETER:}

The three basic parameters for the plan of a rectangular Microstrip Patch Antenna:

Recurrence of activity (f ): The resounding recurrence of the receiving wire must be chosen properly. Receiving wire structured must most likely work in the recurrence go, so thunderous recurrence chose for the plan was utilized to figure the reception apparatus parameters.
Dielectric consistent of the substrate $(\boldsymbol{\varepsilon})$ : The dielectric material ought to be chosen for plan which has a dielectric steady worth. A substrate with a high dielectric steady has been chosen since it diminishes the elements of the receiving wire.

Tallness of dielectric substrate (h): For the microstrip fix radio wire to be utilized in remote gadgets, it is fundamental that the reception apparatus isn't massive. Henceforth, the tallness of the dielectric substrate is additionally chosen.

Consequently, the fundamental parameters for the plan are as per the following:

Resonant frequency $=3 \mathrm{GH}$

Dielectric constant("FR4_epoxy") $=\mathrm{Er}=4.4$

Table 1: Structure Specification

\begin{tabular}{|l|l|}
\hline \multicolumn{1}{|c|}{ Values } & Description \\
\hline $100 \mathrm{~mm}$ & Length of substrate \\
\hline $100 \mathrm{~mm}$ & Breadth of substrate \\
\hline $5 \mathrm{~mm}$ & Height of substrate \\
\hline $100 \mathrm{~mm}$ & Length of ground \\
\hline $100 \mathrm{~mm}$ & Width of ground \\
\hline $50 \mathrm{~mm}$ & Length of rectangularpatch \\
\hline $50 \mathrm{~mm}$ & Width of rectangularpatch \\
\hline $10 \mathrm{~mm}$ & Length of feedline \\
\hline $25 \mathrm{~mm}$ & Width of feedline \\
\hline $10 \mathrm{~mm}$ & Length of inset \\
\hline $5 \mathrm{~mm}$ & Height of inset \\
\hline
\end{tabular}

\section{SIMULATION RESULTS}

This area portrays the reenacted consequences of proposed radio wire. The recreated outcome is completed by the assistance of HFSS v 11 EM test system. The Return Loss, VSWR, Radiation Pattern for four full recurrence of proposed reception apparatus are outlining in Figure. 3,4 and5.

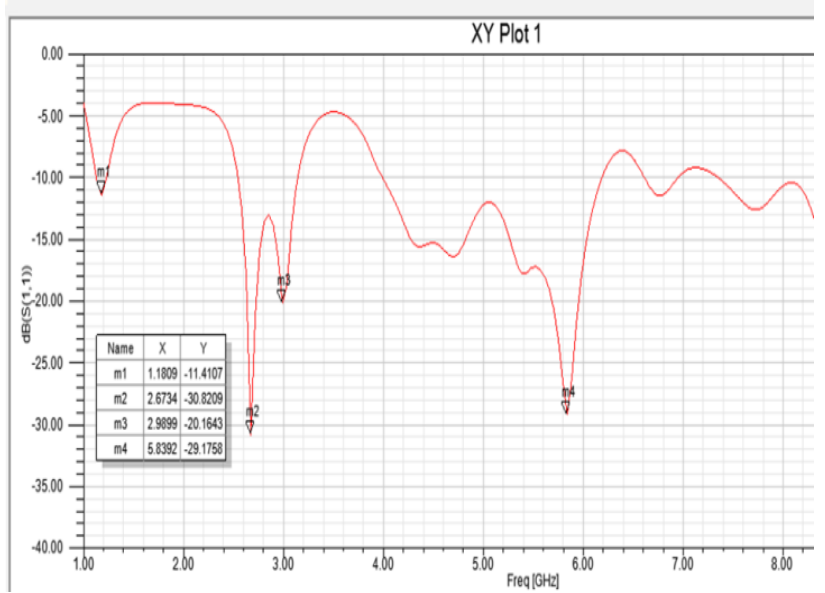

Figure 3: Return Loss

For the proposed antenna resonant frequencies are $2.6734 \mathrm{GHz}$ and $1.1809 \mathrm{GHz}$ and $2.9899 \mathrm{GHz}$ and $5.8392 \mathrm{GHz}$ with return losses $-30.8209 \mathrm{~dB},-11.4107 \mathrm{~dB}$, 20.1643 and $-29.1758 \mathrm{~dB}$ respectively. Due to multiple resonant frequencies the proposed antenna can work on multiple applications such as radio, GSM, Auto-toll roads and container tracking. 


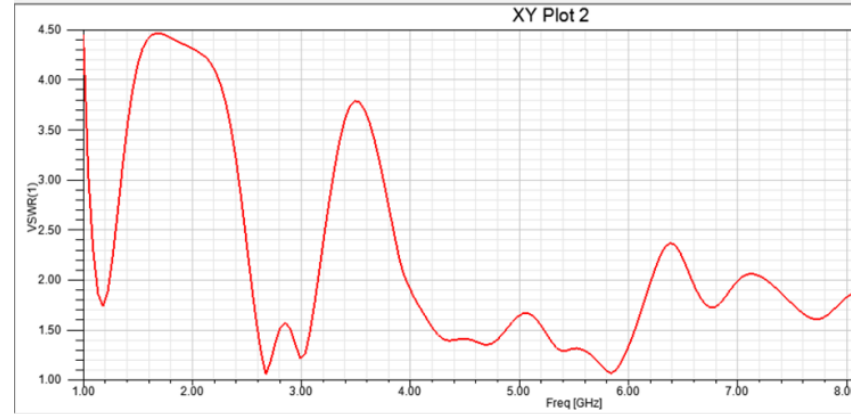

Figure 4: Vswr of Proposed Antenna

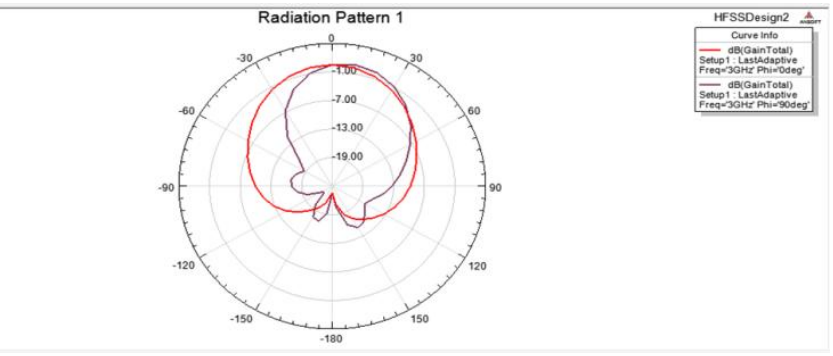

Figure 5: Radiation Pattern(Gain) At 3ghz

Radiation pattern observed is omnidirectional i.e. the antenna will radiate and receive energy equally well in all horizontal directions. In radio correspondence an omnidirectional receiving wire is class of reception apparatus which have a pivot about which radio wave power is emanated symmetrically and upon that hub is zero. They are generally utilized for radio telecom receiving wire and in cell phones that utilization radio, for example, mobile phones, FM radios, Walkie Talkies, GPS.

\section{CONCLUSION:}

A rectangular microstrip fix radio wire is proposed for various recurrence band applications. The reproduction results demonstrate the activity of receiving wire at 2.67 $\mathrm{GHz}, 1.180 \mathrm{GHz}, \quad 2.9899 \mathrm{GHz}$ and $5.8392 \mathrm{GHz}$ with consistency of S-Parameters. The receiving wire planned is best reasonable for working in remote channels i.e., 802/11y WLAN applications, GSM, Auto toll streets and so forth. Microstrip space reception apparatus configuration is introduced here with opening in the focal point of the fix close feed line. The area of the opening is picked to acquire the great radiation qualities at the required frequencies. The inset feed point has effectively reduced info impedance. Both the outcomes are looked at and announced that inset bolstered microstrip opening radio wire gives great radiation properties. The different band reception apparatus demonstrates that with right choice of space measurement and position, a various recurrence reaction can be accomplished, while as yet permitting the utilization of a planar feed substrate.

\section{REFERENCES}

1. Gagandeep Kaur ; R.Madhusudhan Goud ; “ Slotted Rectangular Microstrip Antenna for Dual Band Operation "; Volume 66- No.17, March 2013

2. Nuraddeen Ado Muhammad ; Yusuf Idris ; “ Design and Analysis of Rectangular Microstrip Patch Antenna for Global WLAN Applications Using Matlab and CST
Microstudio Software ", Volume 6 Issue No. 4, April 2016

3. https://www.tutorialspoint.com/wireless_communication/ wireless_communication_overview.htm

4. https://en.wikipedia.org/wiki/Wireless

5. T.Srisuji; C.Nandagopal; "Analysis on microstrip patch antennas for wireless communication"; Feb 2015

6. ZainUl Abedin ; Zahid Ullah ; " Design of a Microstrip Patch Antenna with High Bandwidth and High Gain for UWB and Different Wireless Applications “; Vol. 8, No. 10,2017

7. Balanis C.A. (2005) Antenna Theory: Analysis and Design, John Wiley \& Sons.

8. BiplabBag ; “ Microstrip Slot Antenna for Triple Band Application in Wireless Communication "; Vol:8, No:6, 2014

9. HattanF.AbuTarboush, D.Budimir, R.NilavalanandH.S.Al-Raweshidy, "Connected U-Slots Patch Antenna for WiMAX applications", International Journal of RF \& Microwave CAE, 04/2010; 20(3):279285, DOI:10.1002/mmce. 20431.

10. Amit A. Deshmukh and K. P. Ray, "Multiband Rectangular Microstrip Antennas", IETE Journal of Research, Vol 57 | Issue 5 | sep-oct 2011.

11. Tahsin Ferdous Ara nayna,AKMBaki,"compparitive study of rectangular \& circular microstrip patch antenna in Xband; 9 october 2014

12. Nidhi, Ajay Kumar Jaiswal, Jagtar Singh, "Review paper for multiband and ultra-wide band microstrip patch antenna",Vol.3, issue 5, May 2017.

13. https://en.m.wikipedia.org/wiki/Radiation_pattern

14. VasujadeviMidasala, Dr.P.Siddiah," Microstrip patch antenna array design to improve better gains".

15. S. Kannadhasan ; A.C. Shagar ; "Design and analysis of U-Shaped micro strip patch antenna", 11 July 2017

16. https://www.researchgate.net/post/what_are_the_exact materials_used_in_designing_a_microstrip_patch_antenn

17. Shreya PrabjyotSingh ; Ashish Singh ; Deepak Upadhyay ; Sunilkumar Pal ; Mahesh Munde ; “ Design and Fabrication of Microstrip Patch Antenna at $2.4 \mathrm{Ghz}$ for WLAN Applications using HFSS"

18. https://www.researchgate.net/post/can_anybody_tell_me _why_radiation_box_in_hfss_a_quater_lambda_consider 